\title{
Situating agency, embodied practices and norm implementation in peacekeeping training
}

Article

Accepted Version

Holmes, G. (2019) Situating agency, embodied practices and norm implementation in peacekeeping training. International Peacekeeping, 26 (1). pp. 55-84. ISSN 1743-906X doi: https://doi.org/10.1080/13533312.2018.1503934 Available at https://centaur.reading.ac.uk/78253/

It is advisable to refer to the publisher's version if you intend to cite from the work. See Guidance on citing.

To link to this article DOI: http://dx.doi.org/10.1080/13533312.2018.1503934

Publisher: Taylor \& Francis

All outputs in CentAUR are protected by Intellectual Property Rights law, including copyright law. Copyright and IPR is retained by the creators or other copyright holders. Terms and conditions for use of this material are defined in the End User Agreement.

$\underline{\text { www.reading.ac.uk/centaur }}$

\section{CentAUR}


Central Archive at the University of Reading

Reading's research outputs online 
Situating agency, embodied practices and norm implementation in peacekeeping training

Georgina Holmes

University of Reading

g.holmes@reading.ac.uk 


\begin{abstract}
Applying a Bourdieusian feminist practice theory approach to the study of norm implementation, this article introduces a fourth level of analysis, the embodied subject who is expected to be governed by peacekeeping norms. It does so by examining the training experiences of Rwandan tactical-level female military peacekeepers deployed in mix-gender contingents to UNAMID. It is argued that the pre-deployment training space is a field of norm contestation and negotiation, wherein gendered peacekeeper subject positions and gendered peacekeeping labouring practices are constructed and performed. The research findings suggest that by partially complying with the UN's gender mainstreaming norms, the Rwanda Defence Force strengthens the military's gender protection norms and establishes the sexual division of labour of the mission area. Trained to perform a scripted Rwandan female subject position, some women find they are not adequately prepared for the more challenging situations they find themselves in when working in multi-dimensional peacekeeping operations and devise alternative, informal training practices to better equip themselves prior to deployment. The case study draws on 65 depth-interviews with Rwandan military personnel, trainers and external consultants and non-participatory observations of field exercises.
\end{abstract}

Key words: peacekeeping, gender, pre-deployment training, norms, International Practice Theory

\title{
Acknowledgements
}

An earlier version of this paper was presented at the European Workshops in International Studies, 'Norms and Practices of Peace Operations: Evolution and Contestation', Cardiff, 7-9 June 2017. The author would like to thank Dominik Zaum, Corinne Heaven, Andreas Behnke, Sarah Von Billerbeck, Katia Coleman, Nina Wilén, John Karlsrud, Kseniya Oksamytna, Lucile Maertens, Emily Paddon Rhoads and Marion Laurence for their comments on earlier drafts of this article. The author would also like to thank the British Academy/Leverhulme (Small Research Grant: Ref SG131357) and the Leverhulme Trust (ECF-2015-418) for funding this research; Ilaria Buscaglia, RDF personnel who assisted in coordinating the field research, and the interviewees who agreed to take part in the project. 


\section{Introduction}

How do we conceptualise norm implementation in peacekeeping? How do we account for the ways in which the implementation of institutionalised peacekeeping norms ${ }^{1}$ can lead to variation of practice on the ground? These are the overarching research questions posed by scholars that seek to problematise processes that have largely been overlooked in the norm diffusion/circulation literature. ${ }^{2}$ Norm implementation scholars start from the premise that implementation is a 'distinct process' running in parallel to international norm institutionalisation processes. ${ }^{3}$ Betts and Orchard describe norm implementation as the steps required 'to introduce' an 'international norm's precepts into formal legal and policy mechanisms within the state or organisation in order to routinise compliance', wherein compliance is conceptualised as an 'act' ${ }^{4}$ The conceptual distinction facilitates the study of variance in norm implementation and its effects, even when the act of norm compliance has occurred at the domestic level within the state and its security institutions that engage in peacekeeping. This article contributes to recent theorising of norm implementation by introducing a fourth level of analysis, the embodied subject who is expected to be governed by peacekeeping norms. It does so by examining how UN gender mainstreaming norms are translated into practice in pre-deployment training programmes for tactical-level peacekeepers in Rwanda.

Examining norm implementation processes necessitates a different set of research questions to those posed by norm circulation theorists. The focus shifts away from 'how norms spread' to 'who operationalises norms and under what conditions?' Constructivists define norms as the 'collective expectations for the proper behaviour of actors with a given identity in global politics 5 that 'serve the purpose of guiding behaviour by providing motivations for action'. ${ }^{6}$ Constructivist scholars often distinguish between the level of the international, regional and the domestic (the state) to structure their norm diffusion/circulation models, and have recognised the influence epistemic communities inside the state have in determining how norms are internalised at the domestic level. ${ }^{7}$ They have

\footnotetext{
${ }^{1}$ Karlsrud defines peacekeeping norms as 'norms guiding peacekeeping' (Karlsrud, 2016, 8).

2 See Björkdahl, 2006; Betts and Orchard, 2014; Auteserre, 2014; Paddon, 2014; Paddon, this section; Karlsrud, 2016; 2015; Maertens, this section; Marion Laurence, this section.

${ }^{3}$ Betts and Orchard, 2014, 4.

${ }^{4}$ Betts and Orchard, 2014, 2.

${ }^{5}$ Katzenstein, 1983, 5.

${ }^{6}$ Björkdahl, 2002, 15.

${ }^{7}$ Risse and Sikkink, 1999; Acharya, 2004; 2011; Cardenas, 2004; Betts and Orchard, 2014.
} 
advanced understandings of how international norms are translated, negotiated and contested to challenge the early norm cascade models, which allocated primacy of power and agency to western actors. ${ }^{8}$ However, these theorists have been criticised for failing to locate actors as central to diffusion and implementation, instead ascribing agency to the norm itself. ${ }^{9}$ They have also been criticised for introducing an 'ideational bias' into theorising norm dynamics which positions material interests as secondary in determining what motivates actors to perform, or to change their behaviour. ${ }^{10}$ In contrast, norm implementation theorists acknowledge that ideational, material and institutional factors determine how norms are implemented. ${ }^{11}$ They infer that 'acting persons'12 are agentive and embodied subjects who shape norm implementation processes. How agentive subjects engage in translating institutionalised norms into routinised practices therefore demands greater attention. It requires a conceptual framework that bridges the ideational-material divide, and calls for a rethinking of what is meant by 'internalisation' and 'socialisation' - two metaphors ${ }^{13}$ commonly used by norm diffusion/circulation scholars to denote the moment when a norm is accepted by a state or state institutions.

Peacekeeping training is recognised as a site wherein the UN institutionalised norms that are intended to govern and discipline peacekeeper subjects are diffused and implemented. ${ }^{14}$ Pre-deployment training is conceptualised frequently in the literature as a mechanism or channel through which (liberal peace) norms, values and beliefs, as well as technical skills are transferred to peacekeepers, rather than a field of social practice wherein norms are translated and/or negotiated, consciously or unconsciously, by embodied subjects engaged in the training process. Suspending the regional and local socio-political and economic contexts which shape peacekeeping training and peacekeeping training spaces, this narrow conceptualisation reinforces the assumption that training trainers, standardising training materials and sharing good practice (with the intention of strengthening the flow of knowledge from the core to the periphery) will by default enhance the capabilities of peacekeepers, establish norm compliance and improve operational effectiveness. Two underlying concepts in the peacekeeping training literature - norm diffusion and peacekeeper

\footnotetext{
${ }^{8}$ Acharya, 2004; 2011; Cardenas, 2004; Bloomfield, 2016;

${ }^{9}$ Bucher, 2014.

${ }^{10}$ See Cardenas, 2004; Bigo, 2011; Adler and Pouliot, 2011.

${ }^{11}$ Betts and Orchard, 2014, 13.

12 Bucher, 2014, 748.

${ }^{13}$ Bucher, 2014, 748.

${ }^{14}$ Marco Jowell, 2017; Anne Flaspöler, 2014; Nina Wilén, 2018.
} 
socialisation - support the constructivist emphasis on the ability of norms to 'change the behaviour' of peacekeeper subjects, and in doing so reconfirm the primacy of the norm's agency. As a result, the agency of the peacekeeper subjects who are participants in the training process is eclipsed. ${ }^{15}$

In this article, I develop a feminist reading of French Sociologist Pierre Bourdieu's theory of social practice to examine how gender mainstreaming norms embedded in UN DPKO/DFS policy and training discourse are operationalised by actors during a TCC militaryled pre-deployment training programme. UN gender mainstreaming norms observe that gender equality should be systematically integrated in 'all systems and structures, into all policies, processes and procedures' of peacekeeping, including the cultures of institutions engaged in peacekeeping, and into the 'ways of seeing and doing' peacekeeping and peacebuilding. ${ }^{16}$ 'Biological sex' and culturally constructed concepts of 'gender' should be separated to ensure that all individuals, regardless of their sex, sexuality and gender, are empowered, treated fairly and equally and provided equal opportunities in peacekeeping workforces. ${ }^{17}$

I use practices as my core unit of analysis ${ }^{18}$ to demonstrate how peacekeepers are trained to perform gendered peacekeeping labouring practices prior to deployment. Bourdieu's theory of social practice and his concepts field, habitus and capitals help identify relations of power between international, regional and domestic actors and structures at play in norm contestation. Though Bourdieu has been criticised for overemphasising structure and oversimplifying relations between the dominated and the dominating in his theorising of power ${ }^{19}$, feminist readings of Bourdieu located in political studies and sociology open his theory up to the possibility of observing the agency of subordinated actors, who may work with or against the structures, discourses and practices that govern them. Specifically, feminist theorising of women as both commodities and 'capital-accumulating subjects" ${ }^{20}$ within fields of power, helps us to examine how individual peacekeepers engage in norm contestation during the implementation process.

Focusing on the training experiences of Rwandan tactical-level female military peacekeepers deployed in mix-gender contingents to UNAMID, the article sets out to answer three interrelated questions: 1) How are DPKO/DFS-embedded gender mainstreaming norms

\footnotetext{
${ }^{15}$ Bucher, 2014, 748.

16 Joaquim and Schneiker, 2012, 530.

${ }^{17}$ Zalewski, 2010, 12; Karim and Beardsley, 2017.

${ }^{18}$ Adler and Pouliot, 2011, 5.

19 Lovell, 2000; Skeggs, 2005; Moi, 1991; Bueger and Gadinger, 2014.

${ }^{20}$ Lovell, 2000.
} 
translated into routinised practices during pre-deployment training? 2) What kinds of subject positions are female military personnel trained to enact? 3) How do female peacekeeper trainees engage in norm implementation during the pre-deployment training process? It is argued that the pre-deployment training space is a field of norm contestation and negotiation, wherein gendered peacekeeper subject positions are constructed and reproduced through the embodied performances of institutional practices. The research findings suggest that a 'scripted' Rwandan female peacekeeper subject position is constructed which is based on how RDF senior officers perceive women's use-value within a given mission. Trained to perform this scripted subject position, some Rwandan female military peacekeepers find they are not adequately prepared for challenging working environments and devise alternative, informal training practices to better equip themselves prior to deployment.

Rwanda is an important case study for examining how UN gender mainstreaming norms are operationalised in pre-deployment training programmes. The small African state is among the ten largest contributors of peacekeepers globally and is deploying female military peacekeepers to complex peacekeeping missions including the UN/African Union Mission in Darfur (UNAMID) and the UN Mission in the Republic of South Sudan (UNMISS). Rwanda has deployed troops since 2006 and over the past five years has contributed some 6,000 troops annually, of which 250 (4 percent) are women. ${ }^{21}$ Supporting international gender equality legislation, Rwanda has begun mainstreaming gender its national security policies and architecture and is recruiting more female military personnel, as outlined in its UNSCR 1325 National Action Plan (2009). ${ }^{22}$

The article is divided into four parts. The first part outlines how norms, norm dynamics and agency are conceptualised in the peacekeeping training literature. In the second, the article makes the case that the pre-deployment training space as a field of norm negotiation and contestation wherein gendered peacekeeper subject positions are constructed and performed through embodied practices. The article then examines how UN gender mainstreaming norms embedded in DPKO/DFS policies and training guidance construct women's peacekeeping labouring practices, and illustrates how these norms are operationalised during pre-deployment training. After analysing how a diversity of female military personnel engage in norm implementation during pre-deployment training, the article concludes by reflecting on the explanatory power that a Bourdieusian feminist praxiography contributes to the study of norm

\footnotetext{
${ }^{21}$ Statistics provided by RDF Gender Desk, 9 July 2015.

22 Holmes, 2014.
} 
implementation processes. In conducting this analysis, I offer a significant contribution towards understanding how peacekeeping is gendered, and a conceptual framework to help link agency to norm implementation. The case study draws on 65 depth-interviews with Rwandan military personnel, trainers and external consultants, and non-participatory observations of field exercises.

\section{A Feminist praxiography}

The research strategy employed is based on the methodological approaches located in International Practice theory (IPT) and feminist theory. A Bourdieusian feminist praxiography - the study of gendered logics of embodied practices ${ }^{23}$ - enables a different kind of analysis of norm implementation to constructivist approaches. As Bigo argues, 'constructivism exists only in relation to the empirical study of practices'. ${ }^{24}$ Social relations and institutional processes are not just imbued in 'ideas, language and discourse, they are deposited in bodies and things, and practices emerge' at their confluence. ${ }^{25}$ Practices are intersubjectively created 'competent' and 'incompetent performances' ${ }^{26}$ and 'socially meaningful patterns of action' which are embodied, performed and enacted by actors (subjects) who occupy social positions within a given hierarchically structured field of power. ${ }^{27}$ These social positions, or subject positions, are determined by the field's habitus the naturalised socio-political environment. Naturalised subject positions are 'organised through institutional structures' (the military) and intersectional categorisations such as class, race, gender, religion and dis/ability. Dominant actors may use subject positions to regulate subordinated actors within the field. ${ }^{28}$ Drawing on Butler's theory of performativity, feminists contend that gender is a practice, and embodied practices are gendered. ${ }^{29}$ Wilcox observes that Butler's conceptualisation of gender as 'a 'repeated stylisation of the body' and a 'set of repeated acts' aligns with the practice theorists' 'emphasis on habituated practices of the body, ${ }^{30}$ Subject positions constitute socially accepted, routinised, embodied practices performed by the subject within an institution ${ }^{31}$. Subjects are embodied, and emplaced in a

\footnotetext{
${ }^{23}$ Bueger and Gardinger, 2014, 80.

24 Bigo, 2011, 234.

${ }^{25}$ Pouliot, 2013, 45.

${ }^{26}$ Wilcox, 2016, 801.

${ }^{27}$ Adler and Pouliot, 2011, 6.

28 Skeggs, 2005, p.24.

${ }^{29}$ See Lovell, 2000; Wilcox, 2016.

30 Wilcox, 2016, 795.

${ }^{31}$ Skeggs, 1997, 12.
} 
specific material circumstance (the field and habitus). However, unlike the Subject, which is fragmented and can never be fully known, subject positions are observable. Feminist practice theory examines how gendered, embodied practices are performed by human subjects (actors) within the field of international relations and how the field, and the embodied practices within this field, are experienced by these subjects.

International Practice theorists seek to 'record and construct' practices (praxi), rather than culture (ethno), and establish a 'bottom-up analysis ${ }^{32}$ of 'patterns of action' within the field of practice. Practice theorists argue that 'norms are important', but they 'should not become isolated objects of research'. Instead, they are part of a larger practical 'repertoire of knowledge', or 'background knowledge' acquired by actors in the field. ${ }^{33}$ A feminist theoretical perspective suggests that this background knowledge is informed by collective and personal emotions of actors, as well as intersubjectively produced historical practices, norms and discourses.

To ascertain how UN institutionalised norms were implemented in the Rwanda case study, a three-fold approach ${ }^{34}$ was established to reconstruct a) training and gender mainstreaming practices b) female peacekeeper subject positions and c) positions and struggles between actors in the pre-deployment training field of practice. A mixed-methods approach was used, combining participant observation, depth-interviews and content analysis. Participant observation of field exercises facilitated the mapping of training and gender mainstreaming practices in 'realtime' ${ }^{35}$. Semi-structured interviews with actors who operate within the pre-deployment training field were used to discover women's training experiences; and collect training practices and background knowledge discussed with the interviewees. ${ }^{36}$ These were coded using Nvivo software and relations between codes and thematic patterns were established. Content analysis was used to 'read' ${ }^{37}$ practices located in DPKO/DFS and Rwanda Defence Force (RDF) policies and training materials.

Fieldwork was undertaken at Gako Military Training Academy in Musanze and the Ministry of Defence (MINEDEF) in Kigali, Rwanda between May 2014 and December 2015. Sixty-five semi-structured interviews were conducted with male and female Rwandan

\footnotetext{
32 Karlsrud, 2016, 7.

33 Bueger and Gadinger, 2014, 83

${ }^{34}$ Pouliot, 2013, 48; Bueger and Gadinger, 2014, 83.

${ }^{35}$ Bueger and Gadinger, 2014, 83

${ }^{36}$ Halperin and Heath, 2012, 258.

${ }^{37}$ Bueger and Gadinger, 2014, 85.
} 
military personnel, trainers and external consultants (see table) in Kinyarwanda, English and French by the author, two female research assistants and two translators.

\begin{tabular}{|c|c|}
\hline Research participant & Quantity \\
\hline Female military personnel & \\
\hline $\begin{array}{l}\text { Member of all-female unit in battalion currently } \\
\text { being trained }\end{array}$ & 9 \\
\hline Trained, awaiting deployment & 15 \\
\hline Returned from deployment & 22 \\
\hline $\begin{array}{l}\text { RDF Trainers } \\
\text { Male } \\
\text { Female }\end{array}$ & $\begin{array}{l}6 \\
1 \\
\end{array}$ \\
\hline $\begin{array}{l}\text { External consultants/trainers } \\
\text { Male } \\
\text { Female }\end{array}$ & $\begin{array}{l}2 \\
1\end{array}$ \\
\hline $\begin{array}{l}\text { Senior staff in RDF/Ministry of Defence } \\
\text { Male } \\
\text { Female }\end{array}$ & $\begin{array}{l}8 \\
1\end{array}$ \\
\hline Total & 65 \\
\hline
\end{tabular}

The analysis presented in this article are based on practices observed (identified) and recorded by the author during participant observations, formal and informal research encounters in the pre-deployment training field, and training materials provided by the RDF. Due to restrictions on freedom of speech in post-conflict Rwanda ${ }^{38}$ and the closed institutional structure of the RDF, self-censorship was evident during interviews. Research participants would not discuss whether ethnicity affected their training experiences and this variable is excluded from the study. Research participants were selected by RDF staff in MINEDEF's Peace Support Operations division and by the Office of the Director of Gako Military Training Academy from a pool of peacekeepers who may have been screened and briefed in advance to ensure regularity of performance during research encounters. Several research participants appeared to perform to an RDF institutional (public) transcript or provided what were perceived by the author to be socially acceptable answers for an outsider researcher. ${ }^{39}$ Others diverged from formal narratives and spoke at a more personal and critical level. This discrepancy helped identify the embodied practices female military personnel were expected to perform during training vis-à-vis the practices the women chose to perform, and facilitated reconstruction of the 'scripted' Rwandan female peacekeeper subject position.

\footnotetext{
38 Holmes, 2013, 36-40.

${ }^{39}$ Halperin and Heath, 2012, 259.
} 
Triangulation identified a range of practices and the repetition and routinisation of practices $^{40}$, as did conducting interviews over four field research trips, each lasting 2-3 weeks. To differentiate between types of background knowledge and practices acquired during training, and afterwards during deployment, a comparative analysis of interview transcripts with female peacekeepers that had not deployed and those that had was conducted. Interviews were translated into English and transcribed by three assistants in Rwanda and the UK, although small variations in translation occurred. Research participants consented to the interviews and are referred to by a number, rank and role to ensure anonymity.

\section{Norms and agency in peacekeeping training}

DPKO/DFS outline three training phrases for peacekeepers: pre-deployment training; early deployment (induction) training and ongoing training during deployment. ${ }^{41}$ Under General Assembly resolution A/RES/49/37 (1995), TCCS are responsible for training uniformed personnel and since 2009 are expected to use core pre-deployment training materials (CPTMs) produced by DPKO/DFS and the Integrated Training Service (ITS). Theorising how UN institutionalised peacekeeping norms are implemented in peacekeeping training is an emergent area of research. In the existing literature, critical peacekeeping scholars borrow constructivist definitions of norms and norm dynamics to explain how the politics of global governance play out in peacekeeping training.

First generation scholars writing in the 1990s contended that peacekeepers deployed to multi-dimensional peacekeeping operations require softer conflict resolution skills than the conventional combatant soldier. Transforming the traditional warrior peacekeeper into the 'cosmopolitan peacekeeper' ${ }^{42}$ was the focus, as was improving peacekeeper interactions with host communities to deliver protection of civilian (POC) tasks and support mission-specific peacebuilding efforts. ${ }^{43}$ Peacekeeping training is conceptualised as a mechanism or channel through which to transfer UN institutionalised human rights and protection norms in order to 're-socialise' military personnel as UN peacekeepers; or to transfer technical skills to the peacekeeper. Reflecting constructionist definitions, norms change behaviour and '[re]constitute' peacekeeper subjects. ${ }^{44}$ They are institutionalised at the international level, before

\footnotetext{
40 Pouliot, 2013.

${ }^{41}$ United Nations, 2016a.

42 Curran, 2016, 119.

${ }^{43}$ Betts Featherston, 1998; Duffy, 2000.

${ }^{44}$ Björkdahl, 2002, 21.
} 
cascading to the domestic level once the tipping point is reached, as described in Finnemore and Sikkink's norm life-cycle model. ${ }^{45}$ Norms have socialisation properties and are transferred through military education and training. Betts Featherston draws on Bourdieu's theory of social practice to demonstrate how training 'produces effective peacekeepers. ${ }^{46} \mathrm{~A}$ soldier's behaviours and patterns of action are 'product[s] of habitus' and social positions 'learned from within [the] military' ${ }^{47}$ and may not be appropriate when applied in the peacekeeping mission area, which is a different field and habitus. ${ }^{48}$ Norms therefore set the standards for appropriate behaviour and action. ${ }^{49}$ Where constructivist norm diffusion theories employ the metaphors 'internalisation' and 'socialisation' to explain how norms are accepted at the domestic level, Betts Featherston introduces a fourth level of analysis, claiming that norms transferred via peacekeeping training change a peacekeeper's mindset. However, he infers that the TCC military institution (a singular actor) is a norm-taker or norm-resister, rather than norm-contester of the UN's institutionalised norms, conceptualised as stable and unambiguous.

Second generation scholars apply postcolonial theorising of power relations to foreground the agency of global south TCCs. ${ }^{50}$ 'New peacekeepers', for example from west and east Africa, require 'relatively heavy external assistance and training to deploy troops to peace operations' ${ }^{51}$ Military elites (the new peacekeepers) profit politically and economically from engaging in peacekeeping. ${ }^{52}$ Jowell contends that African militaries are 'adept at adopting and subverting' UN institutionalised norms, suggesting that military elites are normadapters as well as norm-takers and/or norm-resisters. Flaspöler questions whether African peacekeepers can be socialised as 'international peacekeepers', as Betts Featherston presumes, and suggests that TCCs deploy 'hybridised' peacekeeper subjects. ${ }^{53}$ The literature aligns with Acharya's norm circulation model, who evidences the agency and power of domestic (local) actors by demonstrating how these actors 'build congruence' ${ }^{54}$ between institutionalised and domestic norms during implementation.

\footnotetext{
${ }^{45}$ Finnemore and Sikkink, 1998.

${ }^{46}$ Betts Featherston, 1998, 167.

${ }^{47}$ Betts Featherston, 1998, 167.Kats

48 Betts Featherston, 1998, 162.

${ }^{49}$ Katzenstein, 1983, 5.

${ }^{50}$ Flaspöler, 2016; Jowell, 2017; Wilén, 2018.

${ }^{51}$ Wilén, 2018, 4.

52 Beswick, 2014; Wilén, 2018, 4.

53 Flaspöler, 2016.

${ }^{54}$ Betts and Orchard, 2014, 7.
} 
In parallel to this research, gender scholars are examining how UN institutionalised gender mainstreaming norms are implemented in peacekeeping training since UN Security Council Resolution 1325 (Women, Peace and Security) was adopted in 2000. For these scholars, UN gender mainstreaming norms are adaptive and adaptable 55 'constitutive norms' that 'create new actors, interests or categories of action' and 'give meaning to action' ${ }^{56} \mathrm{UN}$ gender mainstreaming norms can be broadened or narrowed once operationalised. When broadened, the norms set policy formation agendas and transform existing organisational structures and practices. When narrowed, they may be 'submitted to other goals than that of gender equality', 'fit into existing policy frames' ${ }^{57}$ and reproduce existing gendered institutional practices. ${ }^{58}$

These scholars acknowledge that training curricular are already gendered before gendered perspectives are integrated. Most empirical studies examine how male uniformed personnel are re-socialised as peacekeepers and focus on preventing male peacekeepers from committing Sexual Exploitation and Abuse (SEA) by enforcing norm compliance through behavioural change. ${ }^{59}$ The studies draw on constructivist norm cascade models to show 1) why UN institutionalised gender mainstreaming norms should be implemented through peacekeeping training; 2) the implications for peacekeeping cultures if TCC military institutions resist norm change. As in Betts Featherstone's analysis, men are products of their domestic military institution's habitus; are taught to behave as hypermasculine warriors and should be resocialised as 'gender sensitive', morally virtuous, 'good' peacekeepers. ${ }^{60}$ Effective gender training 'enlightens' men to the failings of their domestic military habitus. ${ }^{61}$

How female peacekeepers are trained to work in mixed-gender contingents is underexplored, in part due to the prevailing assumption that women naturally possess the softer skills required of the cosmopolitan peacekeeper. ${ }^{62}$ Heineken argues that 'the embodiment of hegemonic masculinities' and 'the hyper-masculine peacekeeping environment' undermine South African women's ability to 'function as equals in peacekeeping' ${ }^{63}$ Pre-deployment training provides an opportunity for military elites to resist

\footnotetext{
55 Joachim and Schneiker, 2012, 529; Krook and True, 2012.

56 Borkdahl, 2002, 16.

57 Joaquim and Schneiker, 2012, 530.

${ }^{58}$ Carreiras, 2006.

59 See Whitworth, 2004; Mackay, 2005; Lyytikäinen 2007; Laplonge, 2015; Carson, 2016.

60 See Higate and Henry, 2009; Whitworth, 2004; Duncanson, 2009; Bevan and MacKenzie, 2012.

${ }^{61}$ Laplonge, 2015; Carson, 2016.

62 Carreiras, 2006; Holmes, 2017; Karim and Beardsley, 2017.

${ }^{63}$ Heineken, 2015, 241.
} 
UN gender mainstreaming norms and reinforce domestic gender protection norms ${ }^{64}$ Women are the vulnerable sex to be protected by men against other(ed) predatory men, and are a 'gendered security risk' ${ }^{65}$ that weakens a deployed battalion's capacity. Women receive the same training as men, but are considered an anomaly in peacekeeping because they cannot embody the peacekeeper masculinity expected of military personnel, a conclusion shared by Sion in her analysis of Dutch pre-deployment training. ${ }^{66}$ These structural limitations prevent women from enhancing operational effectiveness.

Several shared understandings about norm implementation processes may be deduced from this literature review. First, norm implementation constitutes a different process to norm institutionalisation, although implementation and diffusion are used interchangeably. Norms are primarily complied with or rejected, but seldom negotiated. Second, agency and power is assigned to military institutions/military elites (the norm-takers, norm-resisters, and normadaptors), but not to subordinate peacekeeper subjects. In Betts Featherston's analysis, as in the gendered analyses, tactical-level peacekeepers who are expected to be governed by UN institutionalised norms, or who are understood to be governed by the TCC military institutional norms and practices, are passive receivers and conveyors of norms, whose mindsets can be manipulated and changed. Linguistically, the metaphors 'internalisation', 'socialisation', and 'assimulation' ${ }^{67}$ suggest that norms have agency ${ }^{68}$, can penetrate the peacekeeper subject or persuade him/her to behave or think differently. If norms are correctly implemented by the TCC military, 'automatic norm adoption' and acceptance ${ }^{69}$ (internalisation) will occur and change the subordinate peacekeeper's subjectivity. This neglects the underlying, everyday 'agential processes ${ }^{70}$ that determine how subordinate, lower-ranking male and female military personnel participate in norm implementation.

Third, practices matter in norm implementation. Scholars recognise that a relationship exists between norms and practices, and infer the centrality of practices in implementing norms, but there is considerable variety in how practices are understood and employed in the literature. Carson suggests that training is a practice. ${ }^{71}$ Others foreground institutional

\footnotetext{
${ }^{64}$ Karim and Beardsley, 2017.

65 Heineken, 2015, 247.

${ }^{66}$ Sion, 2008.

${ }^{67}$ Heineken, 2015, 244.

68 Bucher, 2014.

69 Bucher, 2014, 749.

70 Bucher, 2014, 749.

${ }^{71}$ Carson, 2016.
} 
practices (rules and processes) and 'peacekeeping practices'. ${ }^{72}$ Gender scholars observe that gender is a practice, and highlight how naturalised gendered power relations are reproduced during peacekeeping training. ${ }^{73}$ However, institutional (training) practices are created and controlled by military elites.

Fourth, material factors determining how and why UN institutionalised norms are implemented is of secondary importance to ideational factors, even though scholars acknowledge that military elites are self-interested and seek to accrue, in Bourdieusean terms, social and symbolic capital which can be converted into material capital. The conviction that ideas change peacekeeper subjectivities eclipses the lived reality that peacekeepers are classed, raced and gendered labouring bodies and material resources (commodities) supplied by the TCC military to the UN. Gender scholars have long vocalised concern that the instrumentalist argument, which emphasises the unique ways women enhance peacekeeping by introducing gender sensitivity into military tasks and into interactions with host country communities, has overshadowed the rights-based argument for including women in peacekeeping workforces. ${ }^{74}$ They challenge assumptions that the operational value of women is dependent on their sex-difference; caution against counting women and essentialising women as peaceful and non-threatening. ${ }^{75}$ Pruitt observes that ' $[\mathrm{w}]$ omen are being marketed, and women's abilities are framed to convince...current decision-makers of the utility of their abilities and knowledge, or to legitimise' institutional practices'. ${ }^{76}$ Crawford and Macdonald suggest that gender mainstreaming is a UN-led demand-driven response to 'past mission failures', rather than a supply-driven response of TCCs. ${ }^{77}$

The appropriation of Bourdieu's theory of social practice to explain how domestic norms are supplanted and gendered peacekeeper subjects transformed overlooks how gendered peacekeeping labouring practices are constructed during the training encounter. Peacekeepers are not just commodities, they are also capital accumulating subjects ${ }^{78}$ who bring their own ideational and material interests to peacekeeping missions ${ }^{79}$, as well as to peacekeeping training. Therefore, the act of norm compliance, non-compliance or partial

\footnotetext{
72 Flaspöler, 2015; Jowell, 2017; Wilén, 2018.

73 MacKay, 2005; Sion, 2008; Laplonge, 2016; Carson, 2016.

${ }^{74}$ See Bridges and Horsfall, 2008; Jennings, 2011; Kronsell, 2012; Simic, 2014; Gizelis and Olsson, 2015; Karim and Beardsley, 2017.

75 See Sion, 2008; Heathcote and Otto, 2014; Simic, 2014; Beardsley and Karim, 2013; Pruitt, 2016; Karim and Beardsley, 2017.

${ }^{76}$ Pruitt, 2016, 78.

77 Crawford and Macdonald, 2013.

78 Lovell, 2000, 20.

${ }^{79}$ Higate and Henry, 2008.
} 
compliance, which occurs during the norm implementation process, carries transactional value both for the TCC and the individual peacekeeper.

Taken together, the ideational bias in the existing peacekeeping training literature foregrounds structure over socially embedded agency and relations of power ${ }^{80}$ in the material training space, and hinders analysis of how a diversity of raced, classed, sexed and gendered peacekeeper subjects engage in norm implementation.

\section{Conceptualising pre-deployment training}

The pre-deployment training space is a field of practice and a site of norm contestation, negotiation and implementation. Actors (subjects) that engage in predeployment training are located within a field and both shape and are shaped by the field's gendered logic of practice (habitus) ${ }^{81}$ The field is a hybrid space in which TCC military actors and external actors from training institutes, other militaries and UN subsidiary bodies (UN Women, DPKO/DFS) engage in curriculum design and delivery and contribute to operationalising UN norms. Norms are contested, adapted, rejected or accepted by the TCC military during 'frictional encounters' with external agents, as they negotiate training content and practice. Informing norm localisation processes, frictional encounters can be productive and may not necessarily lead to the outright rejection of a norm. ${ }^{82}$ Yet, since dominant control over the operationalisation of norms lies with the TCC military, 'norm subsidiarity', defined by Acharya as 'a process whereby local actors create rules [and practices]...to preserve their autonomy from dominance... [and] abuse by more powerful central actors ${ }^{, 83}$, may occur concurrently. For instance, TCC senior military leaders may reject UN gender mainstreaming norms if they perceive that the military institution's established gender regime is threatened. Thus, UN institutionalised norms are adapted by TCC-military senior leaders and trainers (internal norm brokers) and external consultants (external norm brokers) to make them 'workable and practical' in more than one local context - the TCC military and the peacekeeping operation. ${ }^{84}$ Whether a UN institutionalised norm is accepted and complied with, or adapted and partially complied with, depends on whether TCC military elites conceive they will profit symbolically and materially from its implementation.

\footnotetext{
80 Bucher, 2014, 754.

${ }^{81}$ Bourdieu, 1993, 30.

82 Björkdahl and Höglund, 2013, 290.

${ }^{83}$ Acharya, 2011.

${ }^{84}$ Acharya, 2011, 1.
} 


\section{Constructing gendered peacekeeper subject positions}

The pre-deployment training space is a militarised field of power, as well as an educational field of practice wherein subject positions are constructed and negotiated during transfers of knowledge between educators and learners. Through military education and training, male and female personnel are assigned (pre-)constructed subject positions, which they must learn to perform in accordance with the logic of appropriateness within the fields in which they will operate. ${ }^{85}$ Informed by historical, gendered military practices and patterns of action, the training curriculum 'establishes hierarchical relations between different forms of knowledge' and 'generates a network of subject positions in relation to these hierarchies' ${ }^{86}$

For the TCC military, pre-deployment training does not necessarily aim to transform the mindset (consciousness) of subordinate peacekeepers if raising awareness of the military habitus has the potential to disrupt the military's existing power relations. Instead, the aim is to ensure that deployed peacekeeper subjects perform peacekeeping practices to the standardised level of competence required - either by the UN or by the TCC. Accepted norms, then, do not need to be internalised by the peacekeeper subject, but they do need to be implemented and 'incorporated' into the routinised, embodied practices that peacekeeper subjects perform.

Subject positions are constructed according to institutionally and socially recognised (often dialectical) categorisations and sub-categorisations, such as 'man'/'woman', 'masculine'/‘feminine', 'heterosexual'/'homosexual', 'black'/“white'. They are performed repetitively overtime according to the military institution's accepted norms, practices and discourses,${ }^{87}$ leading to the creation of what I call 'scripted' peacekeeper subject positions. How gendered scripted peacekeeper subject positions are constructed is determined by a peacekeeper's perceived use-value. Here, I borrow from the Marxist idea that labouring bodies carry value within a given labour market ${ }^{88}$ and are 'bearers of capital value ${ }^{89}$ for powerful elites. As gender scholars contend, the instrumentalist argument for women's integration into peacekeeping assumes that militarised women's bodies, and the proscribed feminine subject positions military women are expected to perform when undertaking gendered labouring practices, have particular functions in peacekeeping operations and acquire value because they

\footnotetext{
85 Skeggs, 1997, 2.

${ }^{86}$ Skeggs, 1997, 61.

87 Skeggs, 1997, 12.

88 Spivak, 1985, p.3.

${ }^{89}$ Lovell, 2000, p. 24.
} 
are considered to improve operational effectiveness. Peacekeepers are resources (assets) and commodities which TCCs rent out to the UN in exchange for material and symbolic capital (such as international prestige and military experience). If scripted peacekeeper subject positions are performed competently, the TCC may accrue more symbolic and material capital. Therefore, gendered labouring practices peacekeepers performed in the mission are taught and rehearsed during pre-deployment training. Routinised embodied practices performed during training encourage men and women to accept their place within the sexual division of labour of the pre-deployment training space and within the hierarchical structures of both the TCC military and the deployed battalion. ${ }^{90}$

Once operationalised, an accepted norm may no longer be an ideal model of behaviour (performance), since a plurality of relational embodied practices ${ }^{91}$ influence how the norm is implemented during the pedagogic encounter. This plurality of practices create 'norms-inpractice' enacted by trainees during pre-deployment training and once deployed. As Krook and True contend, constitutive norms are 'norms in process'. ${ }^{92}$ Implementing norms and putting them into practice (incorporating ${ }^{93}$ them into embodied practices) cannot completely stabilise a norm, since how practices are performed is dependent on the subject, who may perform them competently or incompetently. Whether embodied practices are perceived to be competently performed will vary according to the different perspectives of the actors within the field. An external consultant may judge that a peacekeeper trainer or trainees' performance is incompetent, while a senior military staff member may presume otherwise, or vice-versa. Bourdieu's theory of practice and his suggestion that the habitus of the pre-deployment training field changes according to the actors operating within it reminds us of the temporality of norm implementation processes. Norms-in-practice, then, are continually negotiated by the subjects engaged in norm implementation. Yet, the repetition and routinisation of embodied practices stabilises implemented norms, albeit precariously.

\section{DPKO/DFS embedded gender mainstreaming norms}

The use-value of tactical-level female military peacekeepers is described in DPKO/DFS's 'Gender Policy for UN Peacekeeping' (2010) and the 'Guidelines for Integrating a Gender Perspective into the work of the UN Military in Peacekeeping Operations' (2010). DPKO/DFS

\footnotetext{
90 Skeggs, 1997, 48.

91 Bigo, 2011, 233.

92 Krook and True, 2012, 110.

93 de Sardan, 2015, 1.
} 
adopt an integrationist (and instrumentalist) approach to gender mainstreaming by emphasising increasing the proportion of female military personnel to deliver specific tasks, and incorporating a gender perspective into established workstreams. This includes applying a gender perspective to tactical-level PoC and law enforcement activities; disarmament, reintegration and security sector reform (DDR/SSR) programmes and Civil-Military (CIMIC) operations aligned to peacebuilding mission objectives. Female military peacekeepers are valued for educating and empowering local women and engaging with perceived vulnerable groups when delivering capacity building projects (currently Quick Impact projects).

DPKO/DFS also interpret UN gender mainstreaming norms as transformative and capable of changing the habitus of peacekeeping workforces and modes of operation (practices) within military, police and civilian components and across multidimensional teams, so that female personnel are equal partners in decision-making at all levels. Within the DPKO/DFS policy discourse, there exists a contradiction in how gender should be practiced. Women's labouring peacekeeping practices are dependent on a close alignment of biological sex and gender, and women are expected to perform as 'female peacekeepers' to deliver specific mission objectives. Yet, DPKO/DFS also support the conscious separation of biological sex and gender to facilitate fair and equal treatment of all staff.

To support implementation of these embedded gender mainstreaming norms, the UN gender directive stipulates that all pre-deployment training modules should 'cover the role and rationale of work for gender equality and the empowerment of women in peacekeeping contexts. ${ }^{94}$ However, the 2009 CPTMs foreground an integrationist approach to gender mainstreaming, incorporating gender perspectives into existing mission objectives. CPTM Unit 3 (Women, Peace and Security), and CPTM Unit 2 (cultural diversity) only briefly conceptualise gender equality in peacekeeping workforces. ${ }^{95}$ Good practice examples demonstrating how gender mainstreaming can facilitate gender equality within peacekeeping contingents are absent. This content was extended in the 2017 CPTMS, as Lucile Maertens observes of the CPTM on environmental issues. ${ }^{96}$ Module Two (Women, Peace and Security) affords greater attention to gendered power structures within peacekeeping, although how TCCs use these training materials is yet to be determined.

\section{Pre-deployment training in Rwanda}

\footnotetext{
94 United Nations, 2010, 16.

95 United Nations, 2010, 2, 47.

${ }^{96}$ Lucile Maertens, this section.
} 
The proceeding case study illustrates how DPKO/DFS embedded gender mainstreaming norms become implemented in the Rwandan pre-deployment training programme for mixed-gender battalions. Overall, the RDF accepts DPKO/DFS integrationist gender mainstreaming norms and rejects transformative gender mainstreaming norms.

\section{Norm contestation and negotiation}

The RDF trained three battalions concurrently at Gako Military Academy. Battalions comprised 800 personnel, with one all-female unit of 10-20 personnel. ${ }^{97}$ During the threemonth pre-deployment training programme, battalions spent two weeks in the classroom and six engaged in field exercises. There was ongoing, ad hoc input from external consultants, primarily the US-funded agency ACOTA and the United States Institute of Peace (USIP) who provided technical advice on setting up practical exercises or occasional training for officers on communication, negotiation and conflict resolution. At the time of the field research, ACOTA consultants (who were US ex-military men) did not design or deliver battalion classroom-based training, but did not regard integrating gender into practical exercises a priority ${ }^{98}$, suggesting there was no conflict of interest between ACOTA consultants and the RDF.

Since RDF trainers delivered classroom-based modules, DPKO/DFS embedded gender mainstreaming norms were operationalised by internal norm brokers rather than external norm brokers (consultants). RDF trainers did not use the CPTM curriculum, nor mainstream gender issues across the training programme, as recommended by DPKO/DFS. They selected elements of the older SGMTs ${ }^{99}$, which presented a narrower, integrationist reading of gender mainstreaming. These older training materials were used in conjunction with modules developed by the African Union and the RDF itself. Thus, the training materials informed a hybridised curriculum, where RDF values and ethics were promoted in the context of teaching military personnel UN/AU modes of operation, as well as the RDF's own modes of operation practiced within Rwandan base camps. According to the male trainers, the hybridised curriculum and relatable domestic examples helped trainees understand theoretical concepts such as 'gender based violence' (GBV). While this hybridised approach can be seen as

\footnotetext{
97 Senior officer 1, interview with the author, 28 May 2014.

98 Brigadier General, interview with the author, 10 June 2014.

99 I thank Anne Flaspöler for this observation.
} 
productive, the limited content selection facilitated partial compliance of UN gender mainstreaming norms.

The RDF only incorporated a gender dimension when teaching modules on preventing SEA, peacekeeper discipline and performance; cultural diversity and PoC. All modules, including the gender module, were taught by RDF officers, rather than in-house gender experts. In interviews, these officers indicated that the UN's more transformative gender agenda was irrelevant for preparing peacekeepers for deployment. Modules were taught didactically as 3045 minute-long lectures by trainers using powerpoint slides to all 800 military personnel in the battalion mess. As an RDF Gender Desk staff member explained, emphasis was placed on ensuring discipline among male troops. ${ }^{100}$ Training objectives specified that the Rwandan male peacekeeper should understand that gender as socially constructed, know the concepts SEA and 'GBV' and understand the different ways conflict affects men, women and children. ${ }^{101}$

Rejection of the UN's transformative gender mainstreaming norms also took effect through norm subsidiarity and in the subtle operationalisation of the RDF's formal (codified and visible) and informal (invisible) gender rules that established the gendered logic of practice of Rwandan base camps within UNAMID and the pre-deployment training space. In Sudan, the RDF's gender protection norms policing the sexual division of labour reproduced stereotypes that 'portrayed women as incapable of providing protection'. ${ }^{102}$ Tactical-level female military peacekeepers who only received TCC-led pre-deployment training worked solely within the Rwandan military base camp unless they were told to visit IDP camps. As in Heinecken and Sion's analyses, women were excluded from performing certain security practices and were confined to 'safe spaces' and 'safe tasks' ${ }^{103}$. They did not join male Rwandan military peacekeepers on short-duration day patrols unless it was known in advance that female military peacekeepers were required, ${ }^{104}$ and they were not allowed to participate in night patrols or long-duration patrols. None of the female peacekeepers interviewed engaged in DDR/SSR programmes, which were not UNAMID priorities. Four women engaged in intelligence gathering, but most who worked with local populations outside the base camp supported empowerment and education projects and discussed human rights, HIV/AIDs awareness and reproductive health with Sudanese women.

\footnotetext{
${ }^{100}$ Female major, interview with the author, 4 June 2014.

${ }^{101}$ Female peacekeeper 6, interview with author, 9 June 2015.

102 Pruitt, 2016, 74.

${ }^{103}$ Karim and Beardsley, 2017, 37.

${ }^{104}$ Female peacekeeper 18, interview with the author, 13 June 2015; Female peacekeeper 16, interview with the author, 10 June 2010
} 
In the $40 \mathrm{~km}^{2}$ training compound, a simulated mission area incorporating three base camps was constructed. The gender order of the UNAMID-Rwandan base camp was reproduced in the simulated mission area: first, in the ordering of the peacekeeping training space itself, which was designed by the RDF, and second in the ordering of training practices in accordance with mission objectives. According to a former Director of Gako Military Training Academy, the simulated base camps were organised identically to Rwanda's base camps in the conflict zone to ensure RDF military personnel experienced the closest they could to mission life. ${ }^{105}$ RDF policy and practice dictated that the all-female unit's tent and bathroom facilities were located next to the officers' accommodation. ${ }^{106}$ These embodied practices reveal the subtle ways in which a network of gendered and classed subject positions is created. Although sexual abuse and harassment should be prevented, the spatial zoning of the simulated base camp positioned all Rwandan women as potential victims requiring protection, but also agents who needed to be vigilant of personal security threats; educated middle-class Rwandan male senior officers were positioned as their protectors, while lower-ranking, (predominantly) working class Rwandan male soldiers were potential aggressors and thus subordinate to male senior officers.

\section{Constructing the Rwandan female peacekeeper subject position}

As in most militaries, male and female personnel train together to form a cohesive team. Though the Rwandan male peacekeeper subject was foregrounded in the classroom, women were expected to perform gendered labouring practices during field exercises. Taskorientated $^{107}$ field exercises, designed to test peacekeepers on knowledge learnt in the classroom $^{108}$ and rehearse peacekeeping labouring practices, addressed gender in narrow terms. During a half-day participant observation, the battalion was presented with two scenarios. In the first, warring factions had set up roadblocks, were conducting ambushes and hindering peacekeepers from reaching IDP camps and isolated, dehydrated Sudanese women. In the second, the battalion encountered IDP demonstrations near the Rwandan base camp. Nine out of the 10 women in the battalion executed basic military tasks within the base camp and one woman, a captain, was an intelligence analyst. In the first scenario, female military personnel performed as the scripted Rwandan female peacekeeper and tasks were assigned according to

\footnotetext{
105 Brig. Gen., interview with the author, 29 May 2014.

${ }^{106}$ Female peacekeeper 23, interview with the author, 5 June 2014.

107 RDF trainer 2, interview with the author, 5 June 2014.

108 RDF trainer 1, interview with the author, 11 December 2014.
} 
their gender. Process-orientated role-plays included teaching local women and girls about gender equality; searching a poor woman's house, rebuilding houses and giving IDPs water. In Rwanda, homosexuality is not illegal, though a strategic silence around LGBT rights in the military and broader society exists. The scripted Rwandan female peacekeeper subject position RDF women rehearsed was implicitly heterosexual, while role-plays focused on responding to women and girl survivors of rape, rather than men and boys. Due to their low rank, the women did not make decisions about managing convoys and ambushes. Peacekeepers were not required to negotiate with female combatants during the patrol exercise because, according to senior RDF staff, it was 'rare to find women in ambushes in Darfur'. 109

All the women interviewed self-identified as gender-neutral peacekeepers. Yet, twothirds spoke of performing a 'female peacekeeper' subject position. One major remarked,

'If I deploy as a female peacekeeper, I'm playing two roles because there are some roles I can play that a men can't play. I interact with female victims, but [a male peacekeeper] will not be able to gather information [from local women], so I'm both a peacekeeper and a female peacekeeper'. ${ }^{110}$

Asked whether she was a peacekeeper or a female peacekeeper, a corporal (a radio operator) responded:

Both. Sometimes I act as a peacekeeper and other times as a female peacekeeper. For example, like those [issues] of gender. Sometimes we go and meet women and they ask us to give them things like bread, water, milk etc. If they see you are a woman, they come to you instead of men. So in that situation, I act as a female peacekeeper, although I am a peacekeeper in all other categories. ${ }^{111}$

As in the field exercises, the constructed gendered peacekeeping labouring practices rehearsed aligned to the instrumentalist approach to integrating women. One private commented:

'The female peacekeeper must console women who have just been raped and teach gender to the population. She must have empathy to console and to teach gender in

\footnotetext{
${ }^{109}$ Senior RDF staff 8, interview with author, 7 June 2014.

${ }^{110}$ Female peacekeeper 7, interview with the author, 9 June 2015.

${ }^{111}$ Female peacekeeper 8, interview with the author, 6 June 2015.
} 
Darfur. I will teach them about the gender factor and teach them [women] how to protect themselves. And I'll teach them to love the military.' 112

Women interviewed understood 'being disciplined' as performing as liberated and empowered, modern Rwandan women and Rwanda ambassadors:

'The first value of a peacekeeper is discipline because we follow the guidelines and rules we are given by our leaders...We are there representing our country so if you fail to perform well, it seems like your country is not disciplining you effectively, and it's [regarded as] a shame [on you and your country].'113

This construction borrowed from the socially recognisable dialectic category of male/female peacekeeper, and a second, raced and class-based dialectic category distinguishing developed, empowered Rwandan women from underdeveloped, disempowered Sudanese women-victims. Here, the UN constructed use-value of female military peacekeepers aligned with the RPF government's constructed use-value of military women as peacebuilders in post-conflict Rwanda. ${ }^{114}$ Building congruence between domestic and DPKO/DFS embedded gender mainstreaming norms, the RDF-constructed scripted Rwandan female peacekeeper performs as educator (diffuser) of Rwandan norms and practices - notably related to conflict resolution and post-conflict development. As one trainee remarked, she will take Sudanese women 'out of violence and teach them the benefits of unity and reconciliation, and teach them how to get out of ethnic conflict'. ${ }^{115}$ Women were also required to perform as the bearer of traditional Rwandan culture. All women interviewed wore traditional dress during cultural exchanges with other military contingents or local populations. One female peacekeeper returnee managed the dance troupe and organised rehearsals. ${ }^{116}$ Fewer men engaged in these gendered embodied practices. Within UNAMID, Rwandan female military personnel were expected to perform two subject positions: the gender-neutral peacekeeper engaged in tactical-level military tasks within the base-camp; and the disciplined Rwandan female peacekeeper who promotes (RPFsanctioned) traditional Rwandan culture and modern values.

\footnotetext{
112 Female peacekeeper 27, interview with the author, 6 June 2014.

${ }^{113}$ Female peacekeeper 29, interview with the author, 7 June 2014.

114 Holmes, 2014; Holmes, 2018.

115 Female peacekeeper 27.

${ }^{116}$ Female peacekeeper 11, interview with the author, 10 June 2015.
} 
The acceptance of the UN's integrationist gender mainstreaming norms appeared to more closely align to the RDF's informal gender norms; helped to stabilise the RDF's gender protection norms, and could be more easily translated into 'norms-in-practice' in the two local contexts within which tactical-level military personnel were required to operate: the UNAMID mission area, and the TCC military. Partially complying with DPKO/DFS embedded gender mainstreaming norms, the RDF increased the commodity-value of their female peacekeepers to accrue more symbolic capital once they deployed, without disrupting the military's gender order.

\section{How female peacekeepers engage in norm implementation}

Female military personnel are not just commodities, but capital accumulating subjects that bring their own ideational and material interests to peacekeeping training. All the women interviewed regarded pre-deployment training as a strategic investment. Yet, when asked whether they felt the pre-deployment training equipped them to perform peacekeeping labouring practices competently, the women responded in diverse ways, depending on their position within the military; how much capital they had access to, and the background knowledge they brought to the training.

Many women - notably lower-ranking and younger privates - felt confident they were equipped with the skills required to deploy to UNAMID, although they often spoke about tactical-level military tasks, rather than the soft skills required for PoC tasks. It was assumed that the background knowledge women acquired growing up in post-conflict Rwanda would enable them to engage effectively with traumatised people in the mission, and many spoke passionately about assisting Sudanese women. A 2nd lieutenant explained,

The RDF, we have experience. For example, the genocide in our country - we saw many things. This made us able to help other countries overcome their war problems'. ${ }^{117}$

Women preparing to deploy also presumed they could communicate easily with Sudanese women, despite their different cultures, religions (all research participants self-identified as Christian), education, age, ability or personal circumstance:

${ }^{117}$ Female peacekeeper 41, interview with the author, 18 November 2015. 
Private: For example, she has been raped. She can't talk to a man but she feels free to talk to me.

Interviewer: Have you been specifically trained on how to talk to a woman that has experienced conflict-related sexual violence?

Private: I have not received that training, but as a person I can imagine what it must be like to speak to her... What is happening in Darfur is almost the same as what happened in Rwanda because they kill each other and [the women and children] are left as widows and orphans. So I really pity them because I know what they are going through and I feel I should counsel them. ${ }^{118}$

For these women, implementing RDF-accepted integrationist gender mainstreaming norms may have carried enough transactional value and they did not request changes to existing training practices. Many performed the scripted Rwanda female peacekeeper subject position in interviews, although it was difficult to ascertain whether performing the scripted subject position was deemed safer than speaking off-script, given their subordinate positions in the military.

Senior, degree-educated officers in their late twenties and thirties who had not deployed demonstrated greater awareness of transformative approaches to gender mainstreaming perhaps background knowledge acquired through their military/political elite networks. These middle-class women, some of whom spoke passionately about the importance of gender equality, felt the training on gender issues was too short, lacked depth about how conflict affected men and women ${ }^{119}$ and focused on good behaviour (norm compliance), rather than on equal opportunity peacekeeping. One female captain requested training on how to 'better implement a gender perspective into the conduct of operations', in intelligence analysis, and wanted to learn how 'gender could be integrated into decision-making'. She believed more complicated scenarios taught in smaller classes would teach peacekeepers how to 'handle problems and execute decisions well'. ${ }^{120}$

These women used their educational and social capital to develop alternative (informal) training practices to source knowledge about the mission and peacekeeping labouring practices they would be required to perform. Practices included talking to previously deployed colleagues; reading training manuals; undertaking self-directed learning and conducting

\footnotetext{
${ }^{118}$ Female peacekeeper 29.

${ }^{119}$ Female peacekeeper 29.

${ }^{120}$ Female peacekeeper 23.
} 
internet searches. The captain and leader of the all-female unit from the battalion trained in 2014 who had a BA degree in international politics, in discussion with her subordinates, organised nightly tutorials which took place in their tent, providing the women space to reflect on the day's learning. This initiative added to the captain's burden of labour suggesting that some female peacekeepers' 'second-shift', or additional, voluntary work ${ }^{121}$, commenced prior to deployment.

Despite these educational investment strategies, which evidence the military women's creative agency, the capacity of female peacekeepers to implement transformative DPKO/DFS embedded gender mainstreaming norms within the mission area was 'constrained by the capital value'122 they represented for the RDF. This can be seen in the responses of women who had returned from UNAMID and their perspectives differed depending on their deployment. Low-ranking women who worked only in their professional military trades within the base camp or mission headquarters considered the pre-deployment training adequate. Women who worked outside the Rwandan base camp in multicultural teams observed gender inequalities within the peacekeeping workforce and talked more about the need for transformative gender mainstreaming initiatives. However, among these women, pre-deployment training was a site where only integrationist gender mainstreaming norms should be implemented, and women focused on discussing how training could better prepare them for mission-specific tasks. Women who worked directly with the local population in challenging contexts considered the training inadequate. These women, who engaged in complex protection duties or worked in isolated teams outside the Rwandan base camp, rejected the idea that soft skills such as communication, negotiation and empathy were feminine traits. Dealing with local people who were traumatised was the primary issue discussed. A degree educated major who had deployed to UNAMID as a liaison officer, felt that training peacekeepers to follow a short protocol for assisting rape survivors did not prepare them for prolonged engagements with survivors over several hours. Referring to the pre-deployment training schedule, she remarked:

All these things were helpful. But when I encountered gender based violence it was not easy... When I was on the ground and reached the [IDP] camp, you find this person who was raped for two or three hours and the people [around her] don't want to

\footnotetext{
121 Pruitt, 2016, 12.

122 Lovell, 2000, 22.
} 
communicate, they don't care about what happened. So you take care of her. You don't go alone, you go with military observers and there must be a female there, the police they must be female. So you get this person, you put her in touch with the NGOs, you take her to hospital, but you need to spend three or four hours with her. ${ }^{123}$

One private required techniques on having 'conversations with local people in order to find out where the problem is and how they really live'. ${ }^{124}$ The Liaison Officer wanted information on the 'psychological impact' CRSV has on survivors. ${ }^{125}$ In parallel with requests for deeper context on gender issues and soft skills, several women wanted more missionspecific scenarios and interactive role-plays for PoC activities. A 2nd lieutenant was critical of the limitations of translating classroom-taught gender theories (which she believed the women did not always understand) during field exercises:

We study [gender issues] theoretically, but in the mission area, when we start putting [theory] into practice there are challenges. In trainings, my mate acts as a refugee and I act as I'm going to help her. But that is like theatre - you can't grasp [the reality] well. ${ }^{126}$

Several returned peacekeepers wanted to out-perform the scripted Rwandan female peacekeeper subject position, believing as one lieutenant explained, 'if women perform their tasks well they will give us more challenging and good tasks, like the ones of men'. ${ }^{127}$ Like the junior women who had not deployed, these women saw implementing RDF-accepted integrationist gender mainstreaming norms as a strategic investment.

\section{Conclusion}

Applying a Bourdieusian feminist praxiography, this article has introduced a fourth level of analysis to norm implementation, the embodied subject who is expected to be governed by peacekeeping norms. A feminist reading of Bourdieu's theory of social practice, with its insistence that subordinated men and women are capital-bearing objects and capital

\footnotetext{
${ }^{123}$ Female peacekeeper 2, interview with the author, 3 June 2014.

${ }^{124}$ Female peacekeeper 11.

125 Female peacekeeper 2.

${ }^{126}$ Female peacekeeper 4, interview with the author, 11 December 2015.

${ }^{127}$ Female peacekeeper 16.
} 
accumulating subjects, enhances the study of norm implementation by demonstrating how these subjects are both compelled and choose to engage in norm implementation. In doing so, the conceptual framework helps to bridge the ideational-material divide found in the norm diffusion/circulation literature. Indeed, Bourdieu regarded rationalist and constructivist paradigms as 'incomplete pictures' and sought a synthesis that would not 'reduce the logic of practice to either instrumental rationality or structural determinism', nor 'reify abstract concepts' such as norms. ${ }^{128}$

Bourdieu's inference of the field and habitus' mutability depending on the actors operating within them, reminds us of the temporality of norm implementation processes. Norms are continually negotiated by the embodied subjects engaged in norm implementation. Yet, as Betts and Orchard observe, there has to be some kind of settling process in order for norms to exist. ${ }^{129}$ In Rwanda, settling occurred via the routinisation and repetition of embodied gendered peacekeeping labouring practices performed by peacekeeper trainees across successive training programmes.

The article also enhances understanding of how through variance in norm implementation, TCCs contribute to sustaining or transforming the gender regimes of peacekeeping operations. As has been observed in other peacekeeping contexts ${ }^{130}$, the RDF partially complied with UN gender mainstreaming norms by foregrounding an integrationist approach, rather than a combined integrationist/transformative approach. This partial compliance allowed male military elites to strengthen the RDF's institutional gender protection norms. Explaining how the gendered labouring practices female peacekeepers are expected to perform in the mission are constructed prior to their deployment, the present study fills an important gap in the existing literature. The study demonstrates how militarized gender protection norms are reproduced and stabilised, and how women become relegated to perceived safe spaces and safe tasks in peacekeeping operations. Female peacekeepers, like male peacekeepers, require more training and support in handling difficult situations involving traumatised populations. Senior military women with more educational and social capital devised alternative (informal) training practices to better equip themselves for deployment and, in one recorded instance, their unit. Yet, women were constrained by the training field's hierarchical structure and this contributed to their marginalisation in UNAMID.

\footnotetext{
128 Pouliot and Mérand, 2013, 31.

${ }^{129}$ Betts and Orchard, 2014, 14.

${ }^{130}$ Carreiras, 2006; Pruitt, 2016; Karim and Beardsley, 2017.
} 
In many ways Rwanda presents a unique case, given the authoritarian government's instrumental use of gender mainstreaming to reconstitute the post-conflict state. ${ }^{131}$ However, the case study illustrates how norm implementation processes in peacekeeping training can take effect. Given that Bourdieu argues that no one field is the same, the conceptual framework developed in this article can facilitate comparative analyses to investigate how agency is linked to norm implementation processes in different peacekeeping contexts.

\section{Bibliography}

Acharya, Amitav. "How Ideas Spread: Whose Norms Matter? Norm Localisation and Institutional Change in Asian Regionalism”. International Organisation. 58 (2004): 239-75.

Acharya, Amitav. "Norm Subsidiarity and Regional Orders: Sovereignty, Regionalism and Rule Making in the Third World”. International Studies Quarterly 55 (2011): 95-123.

Adkins, Lisa and Skeggs, Beverley. (eds.) Feminism After Bourdieu: International Perspectives. (John Wiley \& Sons, 2005).

Adler, Emmanuel and Pouliot, Vincent (eds.) International Practices. (Cambridge: Cambridge University Press, 2011).

Adler-Nissen, Rebecca (ed.). Boudieu in International Relations. (London/New York: Routledge, 2013).

Beardsley, Kyle and Sabrina Karim. "Female peacekeepers and gender balancing: Token gestures or informed policymaking?". International Interactions 39,4 (2013): 461-488.

Betts, Alexander and Orchard, Phil (eds.). Implementation \& World Politics: How International Norms Change Practice. (Oxford: Oxford University Press).

Betts Featherston, A. "UN Peacekeepers and Cultures of Violence". Cultural Survival 19.1 (Spring, 1995).

Beswick, Danielle. "The risks of African military capacity building: Lessons from Rwanda". African Affairs 113:451, 1 (April, 2014): 212-231.

Bevan, Marianne and Megan H. MacKenzie. "'Cowboy' Policing versus 'the Softer Stuff". International Journal of Politics 14,4 (2012): 508-538.

Bigo, Didier. "Pierre Bourdieu and International Relations: Power of Practices, Practices of Power". International Political Sociology 5 (2011), 225-258.

Bueger, Christian and Gadinger, Frank. International Practice Theory: New Perspectives. (Basingstoke: Palgrave Macmillan.)

131 Burnet, 2012; Holmes, 2018. 
Björkdahl, Annika. "Norms in International Relations: Some Conceptual and Methodological Reflections". Cambridge Review of International Affairs 15,1 (2002): 9-23.

Björkdahl, Annika. "Promoting norms through peacekeeping: UNPREDEP and conflict prevention". International Peacekeeping, 13:2 (2006): 214-228.

Björkdahl, Annika and Kristine Höglund. "Precarious Peace: friction in global-local encounters". Peacebuilding 1,3 (2013): 289-299.

Bloomfield, Alan. "Norm antipreneurs and theorising resistance to normative change". Review of International Studies, 42 (2016): 310-333.

Bourdieu, Pierre, The Field of Cultural Production, Oxford: Polity Press, 1993.

Bridges, Donna and Debbie Horsfall. "Increasing Operational Effectiveness in UN Peacekeeping: Toward a Gender-Balanced Force". Armed Forces \& Society, 36,1 (October, 2009): 120-30.

Bucher, Bernd. "Acting abstractions: Metaphors, narrative structures, and the eclipse of agency”. European Journal of International Relations, 20,3 (2014): 742-765.

Burnet, Jennie E. Genocide Lives Within US: Women, Memory, and Silence in Rwanda. University of Wisconsin, 2012.

Cardenas, Sonia. "Norm Collision: Explaining the Effects of International Human Rights Pressure on State Behavior”. International Studies Review, 6:2 (Jun, 2004): 213-231.

Crawford, Kerry and MacDonald, Julia. "Establishing a Marketplace of Women in Peacekeeping." Air \& Space Power Journal - Africa and Francophonie. (2013): 80-96.

Carreiras, Helena. Gender and the Military: Women in the Armed Forces of Western Democracies. London: Taylor \& Francis, 2006.

Carson, Lisa. "Pre-deployment "gender" training and the lack thereof for Australian peacekeepers". Australian Journal of International Affairs, 70,3 (2016): 275-292.

Curran, David. More than Fighting for Peace? Conflict, Resolution, UN Peacekeeping, and the Role of Training Military Personnel, Switzerland: Springer, 2016.

DeGroot, Gerard Jan. "A few good women: Gender stereotypes, the military and peacekeeping”. International Peacekeeping 8,2 (2001): 23-38.

DPKO/DFS, 2010, "Guidelines for Integrating a Gender Perspective into the work of the United Nations Military in Peacekeeping Operations". United Nations, 2010.

Duffy, Tamara. "Cultural issues in contemporary peacekeeping”. International Peacekeeping 7,1 (2000): 142-168. 
Duncanson, Claire. "Forces for Good? Narratives of Military Masculinity in Peacekeeping Operations". International Feminist Journal of Politics 11:1 (2009): 63-80.

Gizelis, Theodora-Ismene and Olsson, Louise (eds.) Gender, Peace and Security: Implementing UN Security Council Resolution 1325. (London/New York: Routledge).

Halperin, Sandra and Heath, Oliver. Political Research: Methods and Practical Skills. (Oxford: Oxfrod University Press, 2012).

Heathcote, Gina and Diane Otto. Rethinking Peacekeeping, Gender Equality and Collective Security, London: Palgrave Macmillan, 2014.

Heinecken, Lindy. “Are Women 'Really' Making a Unique Contribution to Peacekeeping?”. Journal of International Peacekeeping 19, 3-4(2015): 227 - 248.

Higate, Paul and Marsha Henry. Insecure Spaces: Peacekeeping, Power and Performance in Haiti, Kosovo and Liberia. London/New York: Zed Books, 2009.

Holmes, Georgina. Women and War in Rwanda: Gender, Media and the Representation of Genocide, (London/New York: I.B. Tauris, 2013).

Holmes, Georgina. "Gendering the Rwanda Defence Force: A Critical Assessment". Journal of Intervention and Statebuilding, 8:4 (2014): 321-333.

Holmes, Georgina. "Gender, Peacekeeping and the Commonwealth'. The Round Table: The Commonwealth Journal of International Affairs 106:4 (2017): 403-419.

Holmes, Georgina. "Gender and the Military in Post-Genocide Rwanda". Women and Genocide: Survivors, Victims, Perpetrators, ed. Elissa Bemporad and Joyce W. Warren (Bloomington: Indiana University Press, 2018).

Jennings, Kathleen, “Women's participation in UN peacekeeping operations: agents of change or stranded symbols?". NOREF report (September, 2011).

Joaquim, Jutta and Andrea Schneiker. "Changing discourses, changing practices? Gender mainstreaming and security”. Comparative European Politics, 10:5 (December, 2012): 528563.

Jowell, Marco. "The unintended consequences of foreign military assistance in Africa". Journal of Eastern African Studies. (January, 2017).

Karim, Sabrina. "Reevaluating Peacekeeping Effectiveness: Does Gender Neutrality Inhibit Progress?”. International Interactions (September, 2016): 1-26.

Karim, Sabrina and Beardsley, Kyle. Equal Opportunity Peacekeeping. (Oxford: Oxford University Press, 2017.)

Karlsrud, John. Norm Change in International Relations: Linked Ecologies in UN Peacekeeping Operations. (London/New York, 2016.) 
Katzenstein, Peter. The Culture of National Security: Norms and Identity in World Politics, (New York: Columbia University Press, 1983).

Krook, Mona L. and True, Jackie. "Rethinking the life cycles of international norms: The United Nations and the global promotion of gender equality”.18:1 (November, 2010): 103127.

Laplonge, Dean. "The Absence of Masculinity in Gender Training for UN Peacekeepers". Journal of Social Justice 27 (2015): 91-99.

Lovell, Terry. "Thinking feminism with and against Bourdieu". Feminist Theory. 1,1 (2000): $11-32$.

Mackay, Angela. "Mainstreaming Gender in United Nations Peacekeeping Training: Examples of East Timor, Ethiopia and Eritrea". Gender, Conflict, and Peacekeeping, ed. Dyan Mazurana, Angela Raven Roberts and Jane Partpart (Oxford: Rowman and LittleField, 2005).

Moi, Toril. "Appropriating Bourdieu: Feminist Theory and Pierre Bourdieu's Sociology of Culture”. New Literary History, 4 (Autumn, 1991): 1017-1049.

Olsson, Louise and Torunn Tryggestad. Women and International Peacekeeping. London/New York: Routledge, 2001.

Pouliot, Vincent. 'Methodology' in Rebecca Adler-Nissan, Bourdieu in International Relations. (London/New York: Routledge, 2013).

Pruitt, Lesley J. The Women in Blue Helmets: Gender, Policing, and the UN's First All-Female Peacekeeping Unit. (California: University of California Press, 2016).

Risse, Thomas, Sikkink, Kathryn. The socialization of international human rights norms into domestic practices. Cambridge: Cambridge University Press.

Skeggs, Beverley. Formations of Class \& Gender: Becoming Respectable, Sage Press, 1997.

Skeggs, Beverley. "Introducing Pierre Bourdieu's analysis of class, gender and sexuality" in Adkins and Skeggs, Feminism After Bourdieu (Oxford: Blackwell Publishing, 2005).

Sion, Liora. "Peacekeeping and the Gender Regime: Dutch female peacekeepers in Bosnia and Kosovo". Journal of Contemporary Ethnography, $37: 5$ (2008): 561-585.

Simic, Olivera. “Increasing Women's Presence in Peacekeeping Operations: The Rationales and Realities of 'Gender Balance"'. Rethinking Peacekeeping, Gender Equality and Collective Security, ed. Gina Heathcote and Diane Otto (London: Palgrave Macmillan: 2014).

Spivak, Gayatri Chakravorty. "The Scattered Speculations on the Question of Value". Diacritics. Winter (1985): 72-93. 
United Nations. "Core Predeployment Training Materials", United Nations, 2010.

http://repository.un.org/bitstream/handle/11176/89573/CPTM_All.pdf?sequence=1\&isAllow $\underline{\mathrm{ed}=\mathrm{y}}$.

United Nations. “United Nations Peacekeeping Resource Hub”. United Nations, 2016 a.

http://research.un.org/en/peacekeeping-community/Training.

Whitworth, Sandra. Men, Militarism, and UN Peacekeeping: A Gendered Analysis. Lynne Rienner Publishers, 2004.

Wilcox, Laura. "Practising Gender: Queering theory". Review of International Studies. 43:5 (June, 2017): 789-808.

Wilén, Nina. "Examining the links between security sector reform and peacekeeping troop contribution in post-conflict states". Journal of Intervention and Statebuilding (February 2018).

Zalewski, Marysia. "'I Don't Even Know What Gender Is': A discussion of the connections between gender, gender mainstreaming and feminist theory". Review of International Studies, 36,1 (2010): 3-27. 